\title{
Pitriyazis Rozea Olgularında Demografik Özellikler ve İklimsel Faktörlerin İncelenmesi
}

\section{Evaluation of Demographics and Climatic Factors/Disease Relationship in Patients with Pityriasis Rosea}

\author{
Emel Bülbül Başkan, Hakan Turan, Illker Ercan*, Serkan Yazıcı, \\ Güven Özkaya*, Hayriye Sarıcaoğlu
}

Uludağ Üniversitesi Tıp Fakültesi, Deri ve Zührevi Hastalıklar Anabilim Dalı, Bursa, Türkiye

*Uludağ Üniversitesi Tıp Fakültesi, Biyoistatistik Anabilim Dalı, Bursa, Türkiye

\section{Özet}

Amaç: Pitriyazis rozea (PR) akut başlangıçlı, kendi kendine iyileşebilen papüloskuamöz bir deri hastalığıdır. Hastalığın etyolojisi tam olarak bilinmemekle birlikte birçok epidemiyolojik ve klinik çalışma infeksiyöz ajanların hastalığın sebebi olabileceğini desteklemektedir. İnsidanstaki mevsimsel değişiklikler muhtemel infeksiyöz etyoloji için epidemiyolojik kanıtlar olabilir. Bu çalışmada PR olgularının demografik özelliklerini ve hastalıkta iklimsel faktörlerin rolünü incelemeyi amaçladık.

Gereç ve Yöntem: 2000-2005 yılları arasında kliniğimizde takip ettiğimiz PR olgularının dosyalarını retrospektif olarak inceledik. Hasta dosyalarından demografik özellikler ve başvuru tarihleri kaydedildi. 2000-2005 yıllarına ait Bursa ili aylık sıcaklık, basınç, nem, yağış sayısal verileri T.C Meteoroloji Genel Müdürlüğü’nden elde edildi. Hastalığın başlangıç zamanı ile meteorolojik parametreler arasındaki olası bir ilișkiyi incelemek için istatistiksel olarak kümeleme analizi kullanıldı.

Bulgular: İki yüz yetmiş bir kadın, 142 erkek toplam 413 hasta dosyası retrospektif olarak incelendi. Hastaların 88'inde (\%21,3) “madalyon plak" tespit edildi. Pitriyazis rozeanın en sık 20-29 yaş grubunda görüldüğü gözlendi. Hasta sayılarının 2000-2005 yılları arasındaki sayısal dağılımı sırasıyla 51, 57, 80, 75, 63, 87 şeklinde idi. Hastalığın en sık olarak 122 hastada (\%29,5) kış mevsiminde; takiben 101 hastada $(\% 24,4)$ ilkbaharda; 101 hastada $(\% 24,4)$ sonbaharda ve 89 hastada $(\% 21,7)$ yaz mevsiminde başladığı saptandı. İstatistiksel olarak yıllık ve mevsimsel insidanslar arasında anlamlı bir farklılık saptanmadı $(p>0,05)$.

Sonuç: Pitriyazis rozea ile mevsimsel faktörler arasında istatistiksel bir ilişki olmamakla birlikte bu bulgu geniş olgu serili, çok merkezli çalışmalarla desteklenmelidir. (Türkderm 2011; 45: 97-9)

Anahtar Kelimeler: Pitriyazis rozea, demografik özellik, iklimsel özellik, etyoloji, kümeleme analizi

\section{Summary}

Background and Design: Pityriasis rosea (PR) is an acute onset, self-limiting papulosquamous skin disease. The etiology of the disease is totally unknown, however, many epidemiological and clinical studies have suggested that infectious agents may cause the disease. Seasonal changes in the incidence may be an epidemiologic evidence for potential infectious etiology. In this study, we aimed to analyze the demographic data of PR patients and to explore the role of climatic factors in the etiology of the disease. Material and Method: We retrospectively reviewed the patient files of PR cases that had been followed up in our clinic between 2000 and 2005. Demographic data of the patients as well as the date of applications were recorded. Temperature, raining, pressure and humidity data for the City of Bursa for years 2000-2005 were obtained from the General Directorate of Meteorology, Republic of Turkey. Any potential relationship between onset time of PR and meteorological parameters was investigated statistically by using cluster analysis.

Results: We reviewed the medical records of 413 patients, of whom 271 were female and 142 were male. Herald plaque was seen in 88 patients $(21.3 \%)$. Pityriasis rosea was observed predominantly in persons between 20 and 29 years of age (139 patients; $33.6 \%)$. Distribution of number of cases between $2000-2005$ was $51,57,80,75,63$, 87. The highest number of patients was seen in winter (n:122; 29.5\%) followed by spring (n:101; 24.4\%), autumn (n:101; 24.4\%) and summer (n:89; $21.7 \%)$. No statistically significant difference was found between annual and seasonal changes in the incidence of PR ( $p>0.05)$.

Conclusion: We conclude that although the relation between PR and seasonal factors was not statistically significant in our study, multi-centric studies on large series of patients are needed to further investigate this topic. (Turkderm 2011; 45: 97-9)

Key Words: Pityriasis rosea, demographic characteristics, climatic factors, etiology, cluster analysis

Yazışma Adresi/Address for Correspondence: Dr. Serkan Yazııı, Uludağ Üniversitesi Tıp Fakültesi, Dermatoloji Anabilim Dalı, 16059 Bursa, Türkiye Tel.: +90 2242950741 E-posta: serkanyazici@uludag.edu.tr Geliş Tarihi/Received: 27.06.2010 Kabul Tarihi/Accepted: 03.09.2010

Türkderm-Deri Hastalıkları ve Frengi Arşivi Dergisi, Galenos Yayınevi tarafından basılmıştır.

Turkderm-Archives of the Turkish Dermatology and Venerology, published by Galenos Publishing. 


\section{Giriş}

Pitriyazis rozea (PR) akut, kendi kendine iyileşebilen papüloskuamöz bir deri hastalığıdır. Olguların bir çoğunda ilk bulgu "madalyon plak" olup, bunu takiben 5-14 gün içinde özellikle gövde ve ekstremite proksimallerinde klasik lezyonlar gelişir. Hastalığın etyolojisi tam olarak bilinmemekle birlikte birçok epidemiyolojik ve klinik çalışma infeksiyöz ajanların hastalığın sebebi olabileceğini desteklemektedir. İnsidanstaki mevsimsel değişiklikler, dermatologlar arasındaki artmış insidans, aynı aileden birden fazla olgunun bildirilmiş olması muhtemel infeksiyöz etyoloji için epidemiyolojik kanıtlar olabilir ${ }^{1,2}$. Ayrıca genetik eğilim ve psikolojik stres de etyolojiden sorumlu tutulmaktadır. Biz bu çalışmamızda PR olgularının demografik özelliklerini ve hastalıkta çevresel faktörlerin rolünü incelemeyi amaçladık.

\section{Gereç ve Yöntem}

2000-2005 yılları arasında kliniğimize başvuran PR olgularının dosyaları retrospektif olarak incelendi. Hasta dosyalarından demografik özellikler ve başvuru tarihleri kaydedildi. 2000-2005 yıllarına ait Bursa ili aylık sıcaklık, basınç, nem, yağış sayısal verileri T.C Meteoroloji Genel Müdürlüğü'nden; hava kirliliği sayısal verileri Bursa İl Çevre ve Orman Müdürlüğü'nden elde edildi. Hastalığın başlangıç zamanı ile meteorolojik parametreler arasındaki olası bir ilişkiyi incelemek için istatistiksel olarak kümeleme analizi kullanıldı. Denekler arası benzerliklerin hesaplanmasında Gower benzerlik katsayısı kullanıldı. Kümeleme yönteminde or-

Tablo 1. Olgu sayılarının yaş gruplarına göre dağılımı

\begin{tabular}{|l|c|}
\hline Yaş grubu & Olgu sayısı \\
\hline $0-9$ & 18 \\
\hline $10-19$ & 75 \\
\hline $20-29$ & 139 \\
\hline $30-39$ & 84 \\
\hline $40-49$ & 61 \\
\hline $50-59$ & 30 \\
\hline $60-69$ & 3 \\
\hline $70-79$ & 3 \\
\hline Toplam & 413 \\
\hline
\end{tabular}

Tablo 2. Olgu sayılarının aylara göre dağılımı

\begin{tabular}{|l|c|}
\hline Aylar & Olgu sayısı \\
\hline Ocak & 36 \\
\hline Şubat & 51 \\
\hline Mart & 42 \\
\hline Nisan & 29 \\
\hline Mayıs & 30 \\
\hline Haziran & 38 \\
\hline Temmuz & 23 \\
\hline Ağustos & 28 \\
\hline Eylül & 30 \\
\hline Ekim & 38 \\
\hline Kasım & 33 \\
\hline Aralık & 35 \\
\hline Toplam & 413 \\
\hline
\end{tabular}

talama bağlantı metodu kullanıldı. Yıllık ve mevsimsel insidanslar ise istatistiksel olarak ki-kare testi ile değerlendirildi.

\section{Bulgular}

İki yüz yetmiş bir kadın, 142 erkek toplam 413 hasta dosyası retrospektif olarak incelendi. Kadın erkek oranı 1,9/1 idi. Hasta yaşları 1-75 arasında değişmekte olup, ortalama 29,4ะ13,6 idi (ortanca yaş: 26). Hastaların 88'inde $(\% 21,3)$ "madalyon plak" tespit edildi. Hastalığın en sık görüldüğü yaş grubu 139 hasta $(\% 33,6)$ ile $20-29$ yaş grubu idi. 0-9 yaş arası $18(\% 4,3) ; 60$ yaş üzeri 6 hasta $(\% 1,4)$ olduğu saptandı (Tablo 1). Hasta sayılarının 2000-2005 yılları arasındaki sayısal dağılımı sırasıyla 51, 57, $80,75,63,87$ şeklinde idi. Hastalığın başlangıç tarihleri mevsimlere göre incelendiğinde 122 hastada $(\% 29,5)$ kış mevsiminde; 101 hastada $(\% 24,4)$ ilkbaharda; 89 hastada $(\% 21,7)$ yaz mevsiminde; 101 hastada $(\% 24,4)$ sonbaharda başladığı görüldü. Hasta sayılarının aylara göre dağılımı ise Tablo 2'de özetlendi. İstatistiksel olarak yıllık ve mevsimsel insidanslar arasında anlamlı bir farklılık saptanmadı ( $p>0,05)$. Mevsim, sıcaklık, yağış, basınç, nem, SO2, duman değişkenleri bakımından olguların kümeleme analizi ile kümelenmesi incelendi. Kendi içinde homojen, kendi aralarında heterojen olan 4 tane küme belirlendi (Şekil 1). Kümelenmenin oluşmasına neden olan değişkenler incelendiğinde mevsim, sıcaklık, yağış, basınç, nem değişkenleri açısından anlamlı farklılıklar olduğu görülürken ( $p<0,05)$; hastalığa ait klinik değişken bakımından bir farklılık gözlenmedi $(p>0,05)$ (Tablo 3).

\section{Tartışma}

Pitriyazis rozea herhangi bir genetik ve ırksal yatkınlık olmaksızın tüm dünyada yaygın olarak görülen bir deri hastalığıdır ${ }^{3}$. Pitriyazis rozeanın farklı dermatolojik merkezlerden bildirilen insidansı \%0,3-3 arasında değişmektedir ${ }^{4}$. Farklı çalışmalarda hastalığın her iki cinste eşit veya kadınlarda biraz daha sık rastlandığı bildirilmiştir. Chuang ve ark. ${ }^{5} 939$ olguluk çalıșmalarında kadın erkek oranını 1,5/1; Harman ve ark. ${ }^{4}$ ise 391 olgu serilik çalışmalarında bu oranı 1,2/1 olarak bulmuşlardır. Björnberg ve ark. ${ }^{6} 826$ hasta üzerinde yaptıkları çalışmada her iki cinsin eşit olarak etkilendiğini bildirmişlerdir. Çalışmamızda ise kadın hakimiyeti $(1,9 / 1)$ olduğunu gözlemledik.

Singapur'da yapılan 368 vaka serilik bir çalışmada7 madalyon plak görülme oranı \%17 olarak bildirilmişken bizde bu oran biraz daha yüksek olarak bulundu $(\% 21,3)$.

Lagos'tan 352 hasta serilik bir çalışmada hastalığın en sık görüldüğü yaş grubu 10-148; Singapur'dan 214 hastalık bir çalışmada ise 20-24 olarak bildirilmiştir ${ }^{9}$. Biz de, Harman ve ark. ${ }^{4}$ ile Tay ve ark.nın çalışma sonuçlarına benzer şekilde PR'nin en sık görüldüğü yaş grubunu 20-29 olarak saptadık.

PR çocukluk yaş grubu ve yaşlılarda nadir olarak görülmektedir $^{3}$. Bizdeki 10 yaş altı (18) ve 60 yaş üstü (6) olgu oranları da literatür verilerini desteklemekteydi.

Hastalık yıl boyunca görülebilmesine rağmen bazı mevsimlerde daha sık görüldüğü bildirilmiştir. Sudan'da yapılan bir çalışmada ${ }^{10}$ insidansın soğuk ve kuru aylarda; Minnesota'da ${ }^{5}$ yapılan çalışmada soğuk aylarda; Singapur'da9 ${ }^{9}$ Mart, Nisan, Kasım aylarında; Lagos'ta ${ }^{8}$ yağmurlu mevsimlerde; İsveç'te ${ }^{6}$ özellikle sonbaharda insidansın daha yüksek olduğu bildirilmiştir. Nijerya ${ }^{11}$ ve Singapur'da ${ }^{7}$ yapılan çalışmalarda ise anlamlı bir mevsimsel insidans saptanma- 
Tablo 3. Kümeler, klinik değişken ve mevsimsel faktör ilişkisi

\begin{tabular}{|c|c|c|c|c|c|c|}
\hline & Küme 1 ( $n=101)$ & Küme 2 ( $n=101)$ & Küme 3 ( $n=89)$ & Küme 4 ( $n=122)$ & $\mathrm{p}$ & $\begin{array}{l}\text { Küme karşılaştırmaları } \\
\text { ve } p \text { değerleri }\end{array}$ \\
\hline \multirow[t]{3}{*}{$\begin{array}{l}\text { Cins } \\
\text { (Kadın) }\end{array}$} & \multirow[t]{3}{*}{$\% 65,3$} & \multirow[t]{3}{*}{$\% 76,2$} & \multirow[t]{3}{*}{$\% 56,2$} & \multirow[t]{3}{*}{$\% 63,9$} & \multirow[t]{3}{*}{,033 } & $1-2=, 088 \quad 2-3=, 003$ \\
\hline & & & & & & $1-3=, 196 \quad 2-4=, 047$ \\
\hline & & & & & & $1-4=, 826 \quad 3-4=, 254$ \\
\hline Madalyon & $\% 25,7$ & $\% 16,8$ & $\% 22,5$ & $\% 20,5$ & ,473 & \\
\hline Yaş & $30,02 \pm 14,84$ & $28.79 \pm 12,45$ & $28,65 \pm 13,75$ & $29,97 \pm 13,42$ & 877 & \\
\hline \multirow[t]{3}{*}{ Sıcaklık } & \multirow{3}{*}{$15,27 \pm 4,05$} & \multirow[t]{3}{*}{$12,72 \pm 4,44$} & \multirow[t]{3}{*}{$24,07 \pm 1,47$} & \multirow[t]{3}{*}{$5,61 \pm 1,96$} & \multirow[t]{3}{*}{$<, 001$} & $1-2<, 000 \quad 2-3<, 000$ \\
\hline & & & & & & $1-3<, 000 \quad 2-4<, 000$ \\
\hline & & & & & & $1-4<, 000 \quad 3-4<, 000$ \\
\hline \multirow[t]{3}{*}{ Yağış } & \multirow{3}{*}{$2,12 \pm 1,33$} & \multirow{3}{*}{$1,78 \pm 1,23$} & \multirow{3}{*}{$0,42 \pm 0,49$} & \multirow[t]{3}{*}{$3,68 \pm 1,91$} & \multirow{3}{*}{$<, 001$} & $1-2,033 \quad 2-3<, 000$ \\
\hline & & & & & & $1-3<, 000 \quad 2-4<, 000$ \\
\hline & & & & & & $1-4<, 000 \quad 3-4<, 000$ \\
\hline \multirow[t]{3}{*}{ Basınç } & \multirow[t]{3}{*}{$1006,20 \pm 2,26$} & \multirow[t]{3}{*}{$1541,42 \pm 2154,53$} & \multirow[t]{3}{*}{$960,34 \pm 186,80$} & \multirow[t]{3}{*}{$1007,81 \pm 3,22$} & \multirow[t]{3}{*}{$<, 001$} & $1-2<, 000 \quad 2-3<, 000$ \\
\hline & & & & & & $1-3<, 000 \quad 2-4<, 000$ \\
\hline & & & & & & $1-4<, 000 \quad 3-4<, 000$ \\
\hline \multirow[t]{3}{*}{ Nem } & \multirow[t]{3}{*}{$63,46 \pm 16,11$} & \multirow[t]{3}{*}{$63,92 \pm 4,58$} & \multirow[t]{3}{*}{$56,64 \pm 5,65$} & \multirow[t]{3}{*}{$67,94 \pm 3,56$} & \multirow[t]{3}{*}{$<, 001$} & $1-2<, 000 \quad 2-3<, 000$ \\
\hline & & & & & & $1-3<, 000 \quad 2-4<, 000$ \\
\hline & & & & & & $1-4,295 \quad 3-4<, 000$ \\
\hline Mevsim & & & & & $<, 001$ & \\
\hline Sonbahar & $\% 100,0$ & $\% 0$ & $\% 0$ & $\% 0$ & - & \\
\hline Kış & $\% 0$ & $\% 0$ & $\% 0$ & $\% 100,0$ & - & \\
\hline İlkbahar & $\% 0$ & $\% 100,0$ & $\% 0$ & $\% 0$ & - & \\
\hline Yaz & $\% 0$ & $\% 0$ & $\% 100,0$ & $\% 0$ & - & \\
\hline
\end{tabular}

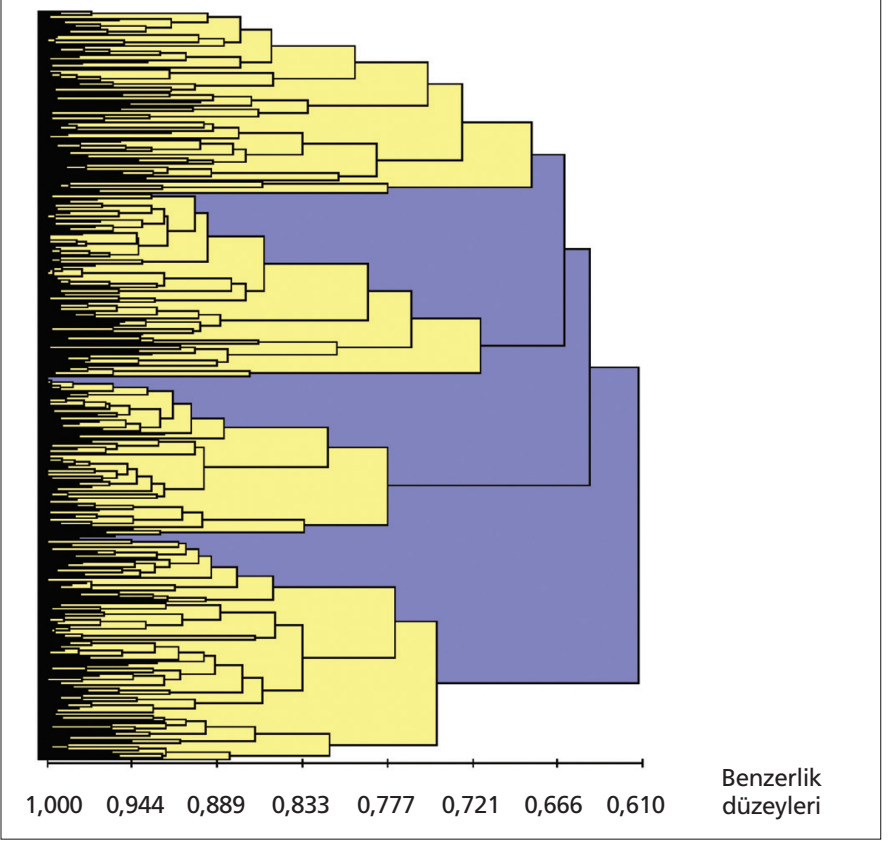

Resim 1: Olgulara ait kümelenmeyi gösteren dendogram

mıştır. Biz de çalışmamızda PR'nin mevsimlere göre görülme sıklığı açısından anlamlı fark saptamadık $(p>0,05)$.

Çevresel faktörler açısından bakıldığında ise mevsimler ve mevsimlere ait sıcaklık, yağış, basınç, nem gibi değişkenler açısından kümelenmeler gözlendi. Bununla birlikte bu oluşan kümelerde klinik değişken açısından farklılık görülmemektedir. Bu durum
PR ve klinik değişken ile mevsimsel faktörler arasında klinik bir ilişki olmadığı düşüncesini akla getirmiştir.

Çalışmamız ülkemizde pitriyazis rozea ile mevsimsel ilişkiyi araştıran tek çalışmadır. Hastalık üzerine çevresel faktörlerin etkisini daha net belirleyebilmek için, çok merkezli çalışmalara ihtiyaç olduğunu düşünmekteyiz.

\section{Kaynaklar}

1. Silva LG, Gardner PS: Pityriasis rosea-a virological study. $\mathrm{Br} \mathrm{J}$ Dermatol 1968;80:514-5.

2. McPherson $A$, McPherson $K$, Ryan $T$ : Is pityriasis rosea an infectious disease? Lancet 1980;2:1077.

3. Bjornberg A, Tegner E. Pityriasis rosea. In Freedberg IM, Eisen AZ, Wolff $\mathrm{K}$ et al. (eds) Fitzpatrick's Dermatology in General Medicine, 5th edition, Mc Graw Hill NY, 1999:541-6.

4. Harman M, Aytekin S, Akdeniz S, Inalöz HS: An epidemiological study of pityriasis rosea in the Eastern Anatolia. Eur J Epidemiol 1998;14:495-7.

5. Chuang TY, Ilstrup DM, Perry HO, Kurland LT: Pityriasis rosea in Rochester, Minnesota, 1969 to 1978. J Am Acad Dermatol 1982;7:80-9.

6. Bjornberg A, Hellgren L: Pityriasis rosea. A statistical, clinical, and laboratory investigation of 826 patients and matched healthy controls. Acta Derm Venereol Suppl (Stockh) 1962;42:1-68.

7. Tay YK, Goh CL: One-year review of pityriasis rosea at the National Skin Centre, Singapore. Ann Acad Med Singapore 1999;28:829-31.

8. Olumide Y: Pityriasis rosea in Lagos. Int J Dermatol 1987;26:234-6.

9. Cheong WK, Wong KS: An epidemiological study of pityriasis rosea in Middle Road Hospital. Singapore Med J 1989;30:60-2.

10. Ahmed MA: Pityriasis rosea in the Sudan. Int J Dermatol 1986;25:184-5.

11. Jacyk WK: Pityriasis rosea in Nigerians. Int J Dermatol 1980;19:397-9. 